ORNL/TM-2012/524

\title{
The Impact of Energy Efficiency Program Information and Incentives
}

October 2012

Prepared by Roderick Jackson

Tim Hendrick Oak Ridge National Laboratory 


\section{DOCUMENT AVAILABILITY}

Reports produced after January 1, 1996, are generally available free via the U.S. Department of Energy (DOE) Information Bridge.

Web site http://www.osti.gov/bridge

Reports produced before January 1, 1996, may be purchased by members of the public from the following source.

National Technical Information Service

5285 Port Royal Road

Springfield, VA 22161

Telephone 703-605-6000 (1-800-553-6847)

TDD 703-487-4639

Fax 703-605-6900

E-mail info@ntis.gov

Web site http://www.ntis.gov/support/ordernowabout.htm

Reports are available to DOE employees, DOE contractors, Energy Technology Data Exchange (ETDE) representatives, and International Nuclear Information System (INIS) representatives from the following source.

Office of Scientific and Technical Information

P.O. Box 62

Oak Ridge, TN 37831

Telephone 865-576-8401

Fax 865-576-5728

E-mail reports@osti.gov

Web site http://www.osti.gov/contact.html

This report was prepared as an account of work sponsored by an agency of the United States Government. Neither the United States Government nor any agency thereof, nor any of their employees, makes any warranty, express or implied, or assumes any legal liability or responsibility for the accuracy, completeness, or usefulness of any information, apparatus, product, or process disclosed, or represents that its use would not infringe privately owned rights. Reference herein to any specific commercial product, process, or service by trade name, trademark, manufacturer, or otherwise, does not necessarily constitute or imply its endorsement, recommendation, or favoring by the United States Government or any agency thereof. The views and opinions of authors expressed herein do not necessarily state or reflect those of the United States Government or any agency thereof. 
ORNL/TM-2012/524

\title{
Energy and Transportation Science Division
}

The Impact of Energy Efficiency Program Information and Incentives

\author{
Roderick Jackson \\ Tim Hendrick \\ Whole-Building and Community Integration \\ Building Technologies Research and Integration Center (BTRIC)
}

October 2012

Prepared by

OAK RIDGE NATIONAL LABORATORY

Oak Ridge, Tennessee 37831-6283

managed by

UT-BATTELLE, LLC

for the

U.S. DEPARTMENT OF ENERGY

under contract DE-AC05-00OR22725 



\section{Table of Contents}

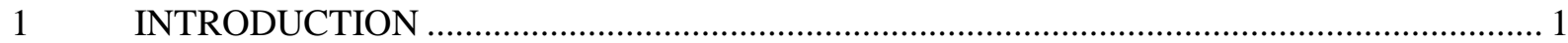

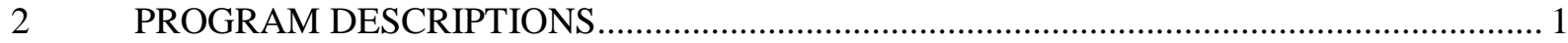

$2.1 \quad$ TVA IN-HOME ENERGY EVALUATION (IHEE) .............................................. 1

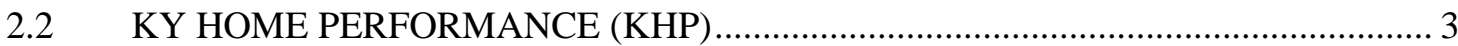

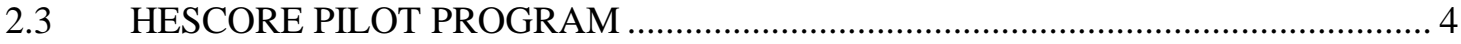

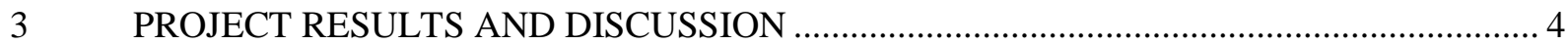

$4 \quad$ CONCLUSION

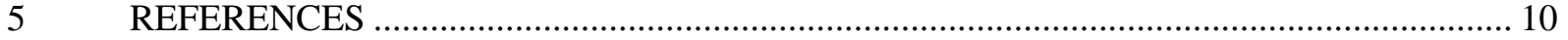

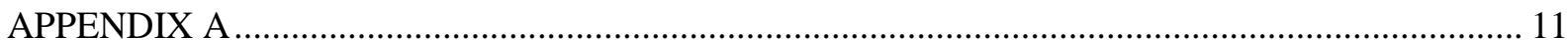




\section{INTRODUCTION}

Residential retrofits are widely viewed as a key resource to improve the national economy and strengthen the nation's energy future by saving homeowners money, creating local jobs, and reducing building energy consumption. However, there has been only limited success in engaging large numbers of homeowners to pursue comprehensive home energy improvements. To increase the market penetration of home retrofits, national programs like the Department of Energy's Home Energy Score ${ }^{1}$ (HEScore), and local programs like the Kentucky Home Partnership (KHP) ${ }^{2}$, have recently been developed. When successfully deployed with existing energy efficiency programs such as the Tennessee Valley Authority's (TVA) In-Home Energy Evaluation (IHEE), national energy efficiency goals that once seemed unattainable may now be within reach.

While national, regional, and local efforts to increase the market adoption of home energy retrofits have expanded, the impact of these programs is not clear. To explore the effectiveness of these types of programs, Oak Ridge National Laboratory (ORNL) partnered with TVA and KHP to conduct a survey of homeowners that participated in the KHP program. A primary component of this survey was to also pilot the HEScore. In this pilot, a subgroup of homeowners that participated in the KHP program were also given an initial HEScore with a incentive tied to the increase in their HEScore after the retrofit was complete. The TVA IHEE program provided an infrastructure for the delivery of both programs and was available to all groups of homeowners to utilize in addition to the KHP and/or HEScore incentives. Metrics such as the percentage of homeowners that completed a retrofit measure, total retrofit investment, and the total number of retrofitted measures were evaluated to determine program impact and are described in this report.

\section{PROGRAM DESCRIPTIONS}

Descriptions of the three energy efficiency programs made available to homeowners in this study are provided below.

\subsection{TVA IN-HOME EVALUATION (IHEE)}

TVA has been running their IHEE program since 2009 and as of April 2012 has completed nearly 40,000 home energy audits. TVA energy advisors are trained and certified by TVA to conduct a thorough visual evaluation of the home. They inspect the attic, crawlspace, living area, water heating, and HVAC systems. They collect data related to all of these home features and record it in their energy modeling software, Real Home Analyzer (RHA). The software

\footnotetext{
${ }^{1} \mathrm{http} / / / \mathrm{www} 1 . e e r e . e n e r g y . g o v /$ buildings/homeenergyscore/

2 http://www.kyhomeperformance.org/
} 
generates a report for the homeowner that includes pictures and recommendations and prioritizes which upgrades are the most cost-effective. The evaluation costs approximately $\$ 150$, but if homeowners install eligible improvements that exceed this cost, the evaluation fee will be reimbursed. While the energy advisors are at the house, they can install up to four $23 \mathrm{~W} \mathrm{CFL}$ light bulbs, low flow sink aerators, and a low flow shower head.

The energy advisors also supply the homeowner with a list of contractors in the TVA contractor network who will be able to perform the work. Homeowners must use a member contractor to be eligible for TVA incentives. The most common upgrades are windows, attic insulation, air sealing, and duct sealing.

Upon completion of the work, the homeowner is scheduled for an inspection. TVA performs an inspection on every job prior to issuing incentives. If the job passes, the inspector notes it in the software and the homeowner's incentive is processed. Homeowners may receive incentives equal to $50 \%$ of the cost of the work, up to $\$ 500$. In addition to the incentives, TVA has a very appealing financing program that allows homeowners to finance their improvements at a competitive interest rate. Table 1 details the home improvements eligible for rebate ${ }^{3}$.

Table 1. Home improvements eligible for rebate under the IHEE program

\begin{tabular}{|c|c|c|c|}
\hline \multicolumn{4}{|c|}{ Eligible Improvements } \\
\hline Energy Efficiency Improvement & Rebate & $\begin{array}{l}\text { Financing } \\
\text { Available? }\end{array}$ & $\begin{array}{l}\text { Self- } \\
\text { Installation } \\
\text { Permitted? }\end{array}$ \\
\hline Replacement windows (must be ENERGYSTAR ${ }^{\circledR}$ qualified) & $\$ 500$ & No & No \\
\hline Storm windows & $\$ 500$ & Yes & No \\
\hline Duct repair/replacement and sealing (existing HVAC only) & $\$ 500$ & Yes & No \\
\hline $\begin{array}{l}\text { Rehabilitation work (minor repair work such as broken glass, } \\
\text { glazing, or prime door replacement, with power company pre- } \\
\text { approval) }\end{array}$ & $\$ 250$ & Yes & Yes \\
\hline $\begin{array}{l}\text { HVAC replacement (must be ENERGY STAR qualified) all heat } \\
\text { pumps included }\end{array}$ & $\begin{array}{l}\$ 250 \text { per } \\
\text { unit }\end{array}$ & $\begin{array}{l}\text { Heat pumps } \\
\text { and dual-fuel } \\
\text { units }\end{array}$ & No \\
\hline Attic insulation/ventilation (must be nonpowered) & $\$ 500$ & Yes & Yes \\
\hline Floor or perimeter insulation and vapor barrier (ground cover) & $\$ 500$ & Yes & Yes \\
\hline Kneewall insulation (in attic) & $\$ 500$ & Yes & Yes \\
\hline Electric water heater insulation and pipe insulation & $\$ 50$ & Yes & Yes \\
\hline Air sealing (including weatherstrip and caulk) & $\$ 500$ & Yes & Yes \\
\hline Central AC/heat pump tune-up & $\begin{array}{l}\$ 150 \text { per } \\
\text { unit }\end{array}$ & Yes & No \\
\hline
\end{tabular}

\footnotetext{
${ }^{3}$ http://www.tva.gov/ee/in home_eval.htm
} 


\subsection{KY HOME PERFORMANCE (KHP)}

KHP is a partnership between the Kentucky Housing Corporation (KHC), Kentucky Department for Energy Development and Independence (DEDI), and Kentucky Finance Administration Cabinet. This program was developed with ARRA funds, and had a goal of 1,200 energy upgrades. TVA overlaps part of southern Kentucky and an agreement was reached between TVA and KHP that TVA energy advisors would perform integrated evaluations and inspections in this area and those homeowners would be eligible for qualifying incentives from both programs.

Audits by BPI certified KHP advisors include the use of a blower door, pressure pan for duct leakage, and combustion safety testing. The advisors still enter all of their data into RHA, which is then automatically uploaded into TREAT, the software used by KHP. Diagnostic evaluations of this type are more expensive than the traditional audit given in the IHEE program. However, for this program, TVA and KHP agreed to subsidize the cost to maintain a $\$ 150$ cost to the homeowner.

Homeowners are eligible for a total of $20 \%$ of the cost of improvements (up to \$2,000) made by KHP approved contractors. ${ }^{4}$ KHP also has a financing offering, but homeowners must choose financing or cash rebate. To qualify for any program incentives under KHP, homes had to meet the minimum program requirements:

- Air sealing of the attic plane, foundation, and "house-to-garage" connections as needed to decrease the air infiltration to $0.4 \mathrm{ACH}_{\mathrm{n}}$,

- Ducts should be sealed if the leakage to the outside of the building envelope exceeds $10 \%$ of the rated fan flow,

- If the home's ceiling insulation was not at least R-19 at the time of the initial inspection, ceiling insulation must be improved to R-38 or better,

- If the home's floor insulation was not at least R-11 at the time of the initial inspection, floor insulation must be improved to R-19 or better,

- Carbon monoxide detectors (if not already present in the home).

In addition to the labor costs of achieving the minimum program requirements, KHP provided incentives for:

- Additional air sealing work beyond the initial program requirements

- ENERGY STAR windows and doors,

\footnotetext{
${ }^{4}$ In order to receive both the TVA and KHP incentive the contractor must be approved by TVA and KHP.
} 
- ENERGY STAR air-source heat pumps,

- If not labeled ENERGY STAR, minimum SEER of $\geq 14.5$ and HSPF $\geq 8.2$ required for split systems and SEER $\geq 14$ and $\mathrm{HSPF} \geq 8$ for package units,

- ENERGY STAR central A/C systems,

- ENERGY STAR gas boilers and furnaces,

- ENERGY STAR water heaters,

- ENERGY STAR programmable thermostats,

- ENERGY STAR closed-loop geothermal heat pumps,

- Lighting - replacement of can lights with ENERGY STAR rated models.

\subsection{HEScore PILOT PROGRAM}

The first 100 homes to sign up for the IHEE and KHP programs qualified for additional incentives under a pilot program of Oak Ridge National Laboratory. In addition to the information regarding household energy use and opportunities for potential savings provided by the other programs, homeowners received both a pre- and post-retrofit Home Energy Score (HEScore). Homeowners were provided an additional incentive to increase post retrofit HEScore through tiered incentives based on the score improvement:

- 3 point improvement $-\$ 1,000$

- 4 point improvement $-\$ 1,500$

- 5 point improvement or more $-\$ 2,500$

The HEScore was presented to homeowners in the form of a scorecard that ranked their home on a scale of 1-10. The homeowners also received information on how to increase their score with specific recommendation on what measures could help bring the biggest increase and tips on saving energy. An example of a HEScore card is shown in Appendix A of this report.

\section{PROJECT RESULTS AND DISCUSSION}

Homes were divided into three groups based on the program incentives for which they qualified. The first group of homes (Group A) participated only in the original TVA program. A second group (Group B) qualified for both the TVA program and the KHP incentive program; while the third group (Group C) qualified for both TVA and KHP program incentives in addition to the HEScore pilot program ${ }^{5}$. The initial home energy evaluation was completed during the months of

\footnotetext{
${ }^{5}$ Homeowners were not given a choice regarding which group for which they were selected.
} 
April 2011 through June 2011 for Group A, October 2011 through December 2011 for Group C, and June 2011 through October 2011 for Group B. Homeowners were initially given three months to complete their retrofits to receive the program incentives. However, it has been the tradition of the TVA program to allow homeowners that complete retrofits after the three initial months to still receive incentives. Since this analysis was conducted approximately six months after Group B received their in home audit, we limited all groups to this implementation period when comparisons between the three groups were made.

Table 2 shows summary survey data across the three groups during the six month period. In general, there was an increase in the average number of retrofit measures implemented as the total incentive increased. However, the marginal benefit of additional incentives decreases between the three groups. For every one retrofit measure implemented in Group A, there was an average of $\$ 313$ of program incentives offered and $\$ 300$ of program incentives provided to the homeowner. In contrast, for every one retrofit measure implemented in Group B, there was an average of $\$ 1,190$ of program incentives offered and $\$ 433$ of incentives provided. Furthermore, for Group C, there were $\$ 2,174$ of program incentives offered and $\$ 556$ of incentives provided, on average, for every one measure.

Table 2. Program results across the three groups of homes ${ }^{6}$

\begin{tabular}{|l|c|c|c|}
\hline & $\begin{array}{c}\text { Group A } \\
\text { (up to \$500 incentive) }\end{array}$ & $\begin{array}{c}\text { Group B } \\
\text { (up to \$2500 incentive) }\end{array}$ & $\begin{array}{c}\text { Group C } \\
\text { (up to \$5000 incentive) }\end{array}$ \\
\hline $\begin{array}{l}\text { Percent of houses that } \\
\text { implemented a retrofit } \\
\text { measure(s) }\end{array}$ & $70 \%$ & $50 \%$ & $59 \%$ \\
\hline $\begin{array}{l}\text { Average number of } \\
\text { retrofit measures }\end{array}$ & 1.6 & 2.1 & 2.3 \\
\hline $\begin{array}{l}\text { Average incentive offered } \\
\text { per retrofit measure }\end{array}$ & $\$ 313$ & $\$ 1,190$ & $\$ 2,174$ \\
\hline $\begin{array}{l}\text { Average total retrofit cost } \\
\text { Average incentive } \\
\text { provided }\end{array}$ & $\$ 2,530$ & $\$ 3,230$ & $\$ 3,630$ \\
\hline $\begin{array}{l}\text { Average incentive } \\
\text { provided per retrofit } \\
\text { measure }\end{array}$ & $\$ 480$ & $\$ 910$ & $\$ 1,280$ \\
\hline
\end{tabular}

Counter to expectations, Groups B and C have a lower implementation percentage than Group A. This difference is most likely due to the manner in which the different incentives and additional

\footnotetext{
${ }^{6} \mathrm{~N}=97$ for Group A, N=100 for Group B, and N=98 for Group C
} 
information (e.g., Home Energy Score) were structured and provided to homeowners. ${ }^{7}$ Even though homeowners in Group A were given fewer incentives and less information, their choices were more basic. The homeowners in Group B and C that were faced with many options for additional incentives could have exhibited decision paralysis ${ }^{8}$ as was cited in Long Island, New York (Kartzman and McKenna, 2012). In addition to the TVA program incentive information and limited implementation requirements provided to Group A, Groups B and C were given a new set of requirements to qualify for the additional incentive of $\$ 2000$ offered by KHP. This "layering" of program requirements and incentives, in contrast to an integrated, yet simple outline of retrofit measures eligible for incentives, can likely account for much of the discrepancy between the implementation percentages. The additional requirements of the KHP program also complicated previously simple transactions for homeowners. For example, when an HVAC replacement was needed or window upgrade desired, the contractor would alert the homeowner of the money available to offset the total cost of the retrofit measure. However, in order to receive the KHP incentive, the homeowner may have to do additional and unplanned weatherization measures. This complication is particularly exacerbated by the fact that more homeowners were made aware of these programs by contractor referrals than any other source. While it is ultimately better for the homeowner to retrofit their home using a whole-house approach, this is not consistent with the past individual measure based approach previously offered in the region. This likely describes why $80 \%$ of contractor referrals resulted in reported retrofits of at least one measure in Group A compared to 55\% and 65\% for Group B and Group $\mathrm{C}$, respectively.

The impact of the "layered structure" also likely contributes to the difference in the rate of retrofit implementations, as shown in Figure 1. Not only do a larger number of homeowners complete retrofits in Group A in comparison to Group C, but the rate of implementation is also faster. In both cases, homeowners were given a 90-day deadline after the initial audit to implement retrofit measures; however, only 37 in Group $C$ had completed a retrofit measure by that time, compared to 53 for Group A. Moreover of the total number of homeowners that completed a home retrofit, $73 \%$ of Group A implemented their measures prior to the 90 deadline compared to $57 \%$ for Group C. The slower implementation rate could also be due to the additional requirements to receive the KHP or HEScore incentive for the homeowners in Group $\mathrm{C}$, which can take longer to implement.

\footnotetext{
${ }^{7}$ A more comprehensive survey with a larger sample size than the sample in the groups in this analysis is warranted to provide a more conclusive assessment.

${ }^{8}$ The concept of decision paralysis is illustrated in Aesop's Fable of the Fox and the Cat. The fox has a "hundred ways of escaping" his enemies, while the cat only has one. When the enemy comes, the cat escapes up a tree while the fox gets confused over his many options and is killed.
} 


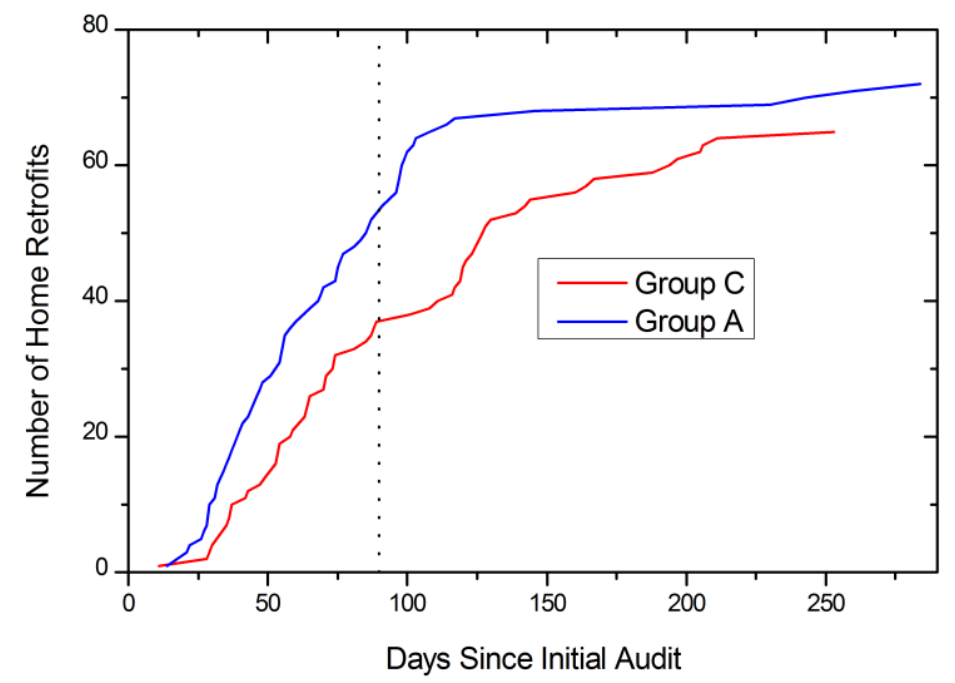

Figure 1. Elapsed number of days since the initial home energy evaluation before a final inspection of completed home retrofits

A primary goal of this study was to examine the impact of the HEScore on homeowner decision making. However the impact of the HEScore, along with accompanying information could not be clearly ascertained. While there is an increase in the implementation percentage, average retrofit measures implemented, and the total retrofit spending in Group $\mathrm{C}$ when compared to Group B, the increase is small and there is no clear distinction between the impact of the additional incentive (up to \$2,500) versus the HEScore. Moreover, the HEScore is intended to be an entry level assessment tool rather than a comprehensive audit (Bourassa, Rainer, Mills, and Glickman, 2012). Because all groups received the TVA IHEE, which also provides recommended retrofit measures, there was no "new information" provided to the homeowner regarding potential retrofit measures. The only additional information Group $\mathrm{C}$ received in comparison to Groups A and B is the HEScore, which is meant to motivate homeowners to pursue a more detailed retrofit work scope based on their current score. However, the ability of the HEScore to increase the homeowner's motivation to pursue a home retrofit is likely hindered by the increased paperwork and information given to each homeowner in the "layered" approach to providing the different efficiency programs.

While the specific impact of the HEScore on homeowner decision making is not clear, other insight from the initial HEScore can be gleaned. Shown in Figure 2 below are all of the homes that were given a HEScore (98) compared with all homes that eventually completed at least one retrofit measure, categorized by the initial HEScore. A first observation from the chart is that the majority of homes (67) that received an audit had an initial HEScore between 3 and 6. The overall average for all HEScores is 4.4. This is reasonable, since homeowners would not likely make the initial investment of $\$ 150$ unless they believed their home was in need of efficiency improvements. 


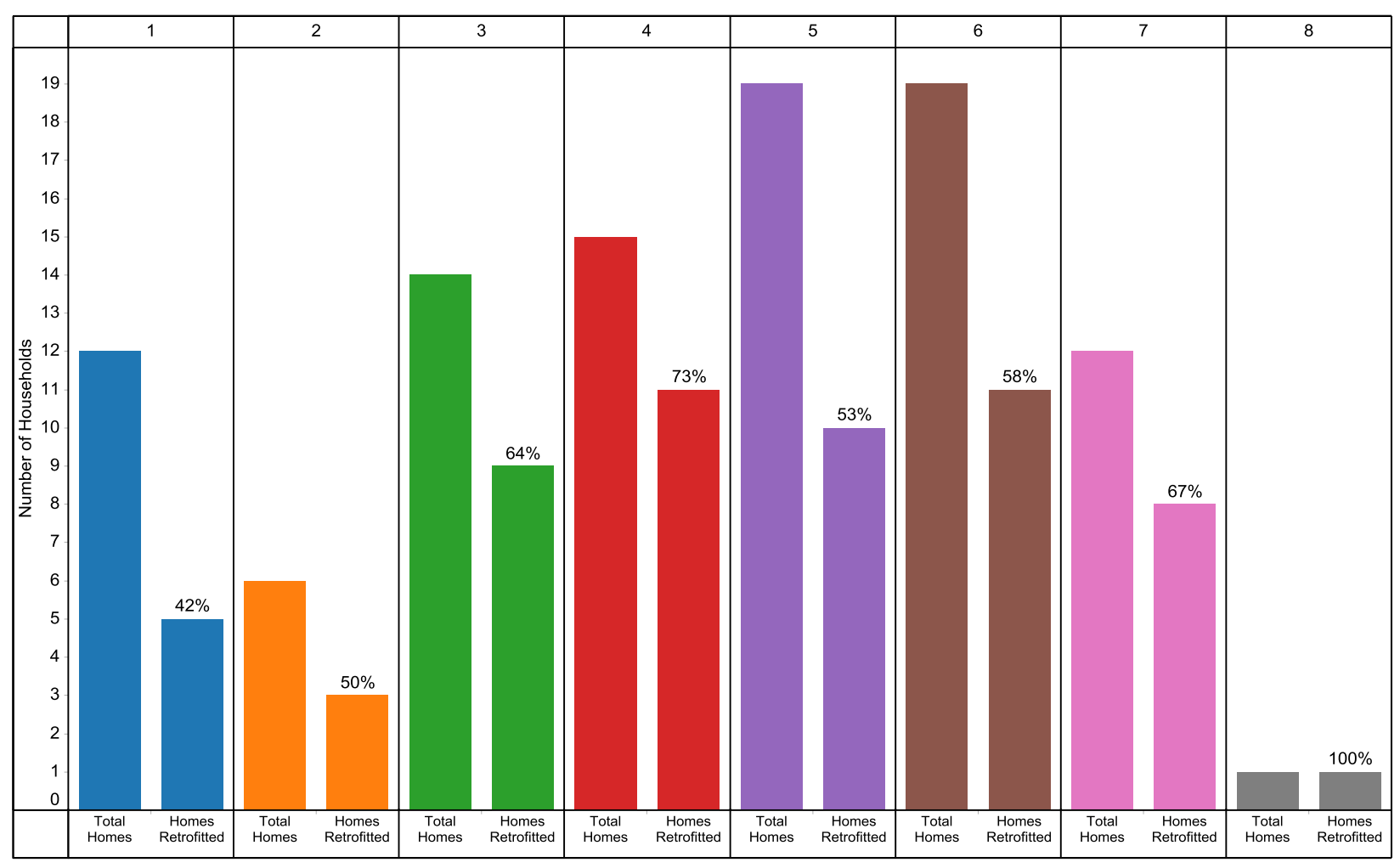

Figure 2. Number of households that received a HEScore compared to homes that completed a home retrofit ${ }^{9}$

The implementation percentage varies by HEScore with no overall distinct trends. However, it is noteworthy that the two lowest implementation percentages occur in the homes with HEScores of 1 or 2 . A possible cause for this difference could be that homes with lower HEScores likely have to implement more measures than homes with higher HEScores. This can be seen in Figure 3 , where the average number of implemented measures decreased with increasing HEScore. A larger sample size of homes is needed to further verify this hypothesis.

\footnotetext{
${ }^{9}$ The homes are grouped by HEScore ranging from 1-8. The implementation percentage of each subgroup is shown in the chart.
} 


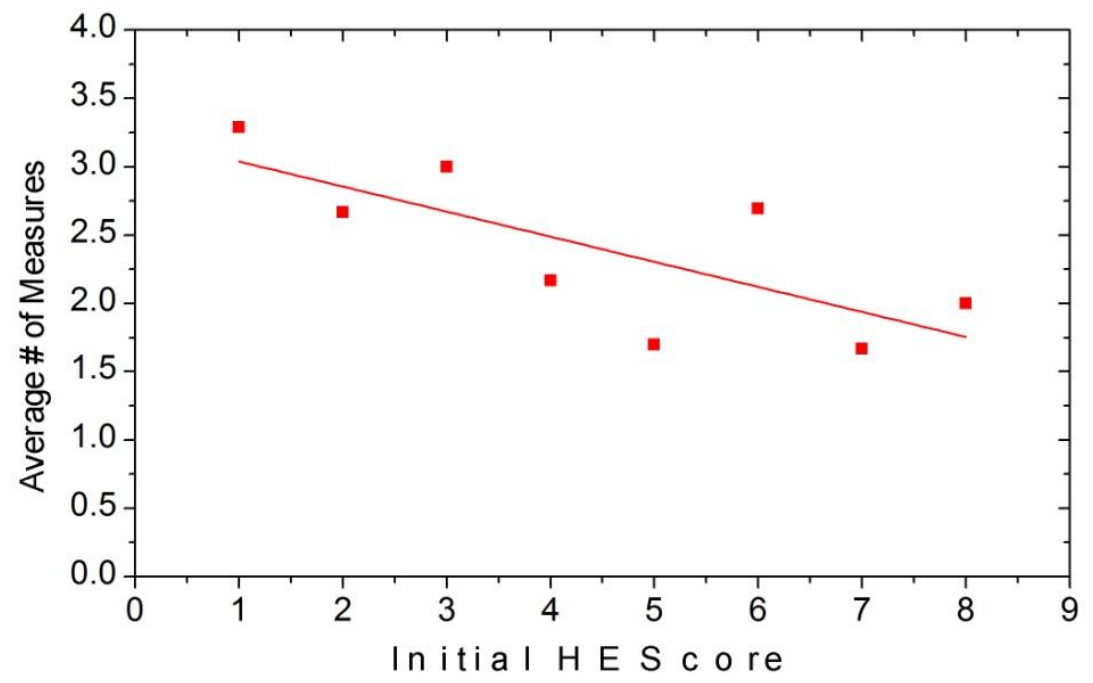

Figure 3. Average number of implemented retrofit measures plotted as a function of the initial HEScore.

\section{CONCLUSION}

Surveys of three groups of homeowners in the TVA region of southern Kentucky were analyzed to determine the impact of program incentives and information on retrofit decisions. Program structures with a varying composition of incentives, retrofit measure eligibility, and general requirements were offered to the different groups. Homeowners who were offered more incentives generally completed more retrofit measures and spent a larger amount of money on their retrofit. On the other hand, there were a smaller percentage of homeowners that received an initial home evaluation who completed a retrofit in the groups that were offered a greater incentives and retrofit information. This is likely attributed to the structure of the program offerings. The additional $\$ 2,000$ to $\$ 4,500$ in incentives was not sufficient to overcome the complexity and probable confusion of the increased and different requirements of the programs they had to combine to receive their full benefit. The increased requirements had an ultimate goal of promoting whole-house retrofits instead of single measure replacements, which is an admirable and more optimal approach to home energy retrofits. However, the program structure as delivered in this study was not sufficient to reduce homeowner confusion and transaction costs. Future programs should be developed in a simple, integrated manner to fully achieve the desired outcome.

This study could not ascertain a clear impact of the HEScore, in part due to the program structure of layering the HEScore and associated incentives to increase the post-retrofit score. Since the HEScore was a different program layered on top of the IHEE and KHP programs, it is likely that the homeowners could not ascertain the true value the HEScore provides of giving a comparison with other homes in their region. Moreover, because the HEScore recommendations were not substantially different than the recommendation of the IHEE and KHP programs, its ability to 
motivate homeowners to do more than if they only received the IHEE and/or KHP was likely mitigated.

\section{REFERENCES}

Bourassa, N. J., L. Rainer, E. Mills, and J. Glickman. 2012. “The Home Energy Scoring Tool: A Simplified Asset Rating for Single Family Homes." In Proceedings of the 2012 ACEEE Summer Study on Energy Efficiency in Buildings. Washington, D.C.: American Council for an Energy-Efficient Economy.

Kartzman, D. and S. McKenna. March/April 2012. "Eliminating Decision Paralysis on Long Island." Home Energy. 


\section{Appendix A}

Sample Home Energy Score Label (Page 1)

\section{HOME ENERGY SCORE}

Address 1
Total Energy Home Size Air Conditioning Yes
218 MBTUs / year 1,310 square feet

Yes
Climate Zone

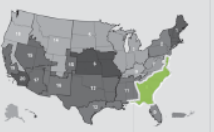

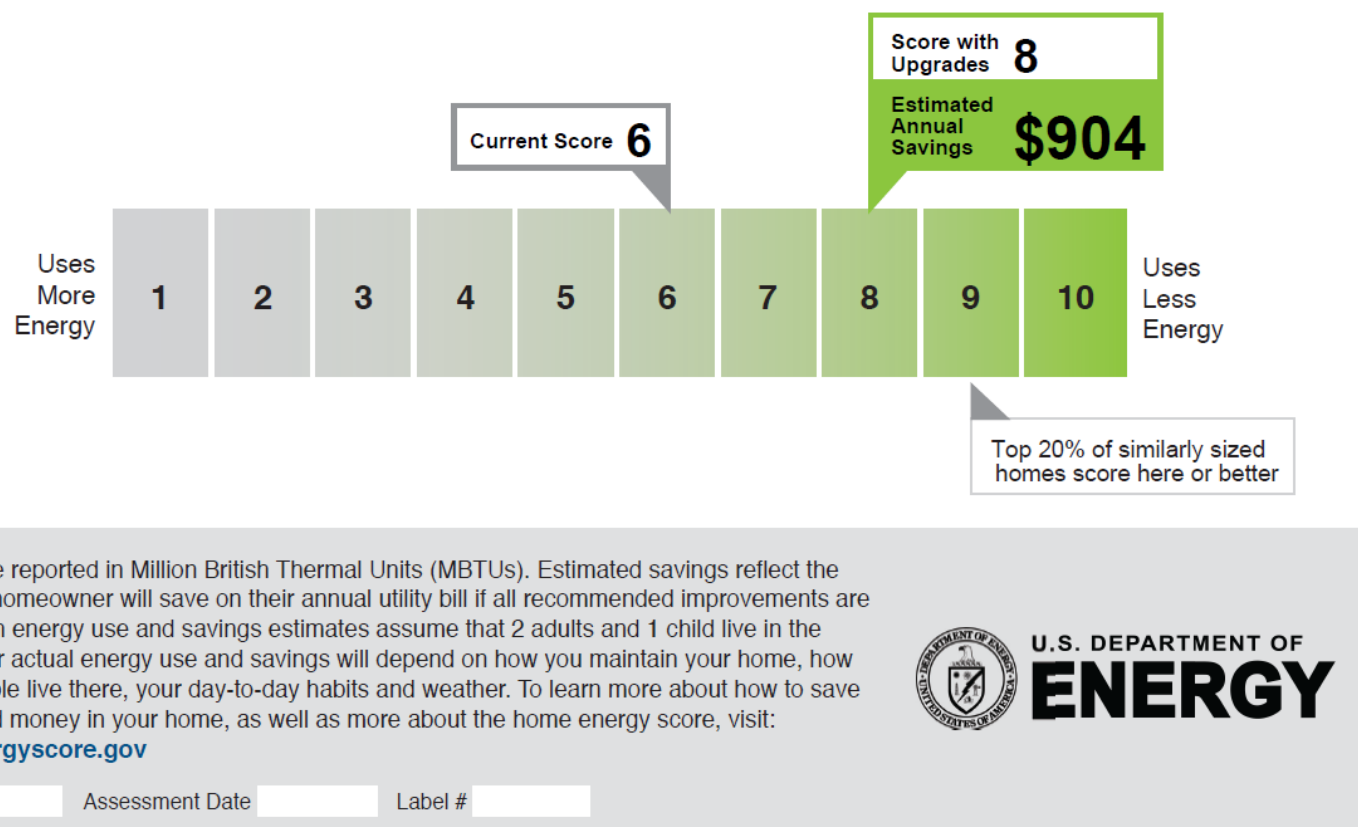




\section{Sample Home Energy Score Label (Page 2)}

Most home owners can reduce their energy bills and increase the comfort and safety of their home by changing some basic habits and doing more routine maintenance. Here are some easy ways to save energy and money. Savings from these measures are not included in the Home Energy Score.

\section{Refrigerator/Freezer}

- If your extra refrigerator is only used once in a while, unplug it and prop the door open when it's empty. - If your extra refrigerator doesn't have much in it, consider replacing it with a smaller Energy Star model.

\section{Laundry}

- Use cold water to wash your clothes. Most detergents clean just as effectively and clothes don't fade as fast.

- Hang your clothes on a line to dry, when appropriate.

a If you use a clothes dryer, set the timer to Autodry so the dryer stops when your clothes are dry. This saves energy and is better for your clothes.

v Clean the dryer lint trap before each use. Clean the dryer vent hose every 6 months, more if you dry a lot of clothes. Be sure your vent hose is free of kinks.

\section{Heating and Cooling}

- Install a programmable thermostat.

- During the winter, lower the thermostat setting at night and when the house is empty.

- During the summer, raise the thermostat setting at night and when the house is empty.

- Avoid the desire to turn the thermostat temperature way up or way down to make the house warmer or colder. It doesn't heat or cool the house any faster but it uses more energy.

- Use ceiling fans alone or with air conditioning. Remember to turn them off when you leave.

- Change your furnace filter every two months (during summer too, if you have central air conditioning). Do it more frequently if you have pets or see that the filters are more than a little dirty.

- Bleed the air out of the radiators within a month of turning the boiler on each winter. Don't block vents and radiators with furniture.

- Install reflectors behind the radiators on outside walls.

- Keep about 2 feet of space cleared around your outside air conditioner/heat pump compressor.

\section{Curtains and Blinds}

- On summer days, close window shades and curtains on the south and west side of the house. On winter days, open them.

- On winter nights, close all window shades and curtains.

\section{Lights}

When you leave a room, turn lights off.

- Replace incandescent bulbs with compact florescent lights (CFLs).

\section{Computers and Other Electronics}

- Use the energy saver settings on computers and other electronics so they go to sleep when you are not using them.

- Plug groups of electronics together into one power strip. Turn off the whole powerstrip when they are not in use.

\section{Water}

Fix leaky faucets and running toilets right away.

Install low-flow showerheads and faucet aerators.
Buying and Replacing Appliances, Windows and Other Equipment

When you buy or replace appliances, windows or other equipment, be sure to pick ones that have an ENERGY STAR label. If there are no ENERGY STAR choices, compare the products' energy use specifications and pick one that is more energy efficient.
Whole House upgrades save energy and money and can make your home more healthy, comfortable and safe to live in.

For even bigger savings, ask a certified energy professional about "whole house" energy upgrades. Qualified professionals can help you pick the right kind and size of equipment and make sure it is installed correctly. They also help you understand the health, comfort and safety considerations of your decisions when planning improvements. 
Sample Home Energy Score Label (Page 3)

HOME UPGRADE RECOMMENDATIONS

Address

Improvements recommended now

These upgrades can help you save energy right away.

Ducts: Have vour ducts professionally sealed to reduce

leakage.

Basement/crawlspace: Insulate the floor above unconditioned

space to at least R-19.

Attic: Increase attic floor insulation to R-38.

Air tiahtness: Have a professional seal the aans and cracks

that leak air into your home.

\section{Recommendations for when you need to replace equipment}

These recommendations will help you save energy when it's time to replace or upgrade.

Water heater: Pick one with an ENERGY STAR label.

Furnace: Pick one with an ENERGY STAR label.

Windows: Pick ones with an ENERGY STAR label.

$\$ 70$

$\$ 190$

$\$ 110$
430

1,260

980

It is important to consult a certified energy professional to ensure improvements are made properly and take into account health, comfort, and safety. Proper installation, including details such as complete coverage of rigid insulation and taping the seams, is critical to achieving energy savings. As with any major purchase, you should seek more than one cost estimate before making a buying decision.

How are savings calculated?

These estimates are based on standard energy use patterns of 2 adults and 1 child. Actual energy bills and projected savings will vary according to the number and type of appliances, the number of occupants and their behavior, and weather.

\section{What does payback period mean?}

For improvements recommended now, simple payback reflects the number of years it will take to cover your upfront costs. For recommendations concerning future equipment replacement, payback time is the number of years it will take for your savings to add up to your upfront cost if you buy an Energy Star, or high-efficiency unit, instead of a lower-efficiency one.

Payback periods will vary depending upon local energy costs and the costs of improvements in your area. Only measures with paybacks of 10 years or less are included. If you take into account the opportunity cost of money, the payback time is longer. 